\title{
Effect of chromosome constitution variations on the expression of Turner phenotype
}

\author{
A.V.S. Bispo ${ }^{1}$, L.O. dos Santos ${ }^{1}$, P. Burégio-Frota ${ }^{2}$, M.B. Galdino ${ }^{1}$, \\ A.R. Duarte ${ }^{3}$, G.F. Leal ${ }^{3}$, J. Araújo ${ }^{4}$, B. Gomes ${ }^{4}$, E.M. Soares-Ventura ${ }^{5}$, \\ M.T.C. Muniz ${ }^{5,6}$ and N. Santos ${ }^{1}$ \\ ${ }^{1}$ Departamento de Genética, Centro de Ciências Biológicas, \\ Universidade Federal de Pernambuco, Recife, PE, Brasil \\ ${ }^{2}$ Laboratório de Pesquisa Translacional Prof. C. Anthony Hart, \\ Instituto de Medicina Integral Prof. Fernando Figueira, Recife, PE, Brasil \\ ${ }^{3}$ Unidade de Genética Pediátrica, \\ Instituto de Medicina Integral Prof. Fernando Figueira, Recife, PE, Brasil \\ ${ }^{4}$ Unidade de Endocrinologia Pediátrica, Hospital das Clínicas, \\ Universidade Federal de Pernambuco, Recife, PE, Brasil \\ ${ }^{5}$ Centro de Oncohematologia Pediátrica de Pernambuco, \\ Hospital Oswaldo Cruz, Universidade de Pernambuco, Recife, PE, Brasil \\ ${ }^{6}$ Instituto de Ciências Biológicas, Universidade de Pernambuco, \\ Recife, PE, Brasil \\ Corresponding author: N. Santos \\ E-mail: santos_neide@yahoo.com.br
}

Genet. Mol. Res. 12 (4): 4243-4250 (2013)

Received August 6, 2012

Accepted November 24, 2012

Published March 13, 2013

DOI http://dx.doi.org/10.4238/2013.March.13.13

ABSTRACT. Turner syndrome (TS) is a chronic disease related to haploinsufficiency of genes that are normally expressed in both $\mathrm{X}$ chromosomes in patients with female phenotype that is associated with a wide range of somatic malformations. We made detailed cytogenetic and clinical analysis of 65 patients with TS from the region of Recife, Brazil, to determine the effects of different chromosome constitutions on expression of the TS phenotype. Overall, patients with X-monosomy exhibited a tendency to have more severe phenotypes with higher 
morbidity, showing its importance in TS prognosis. Additionally, we found rare genetic and phenotypic abnormalities associated with this syndrome. To the best of our knowledge, this is the first case of $45, \mathrm{X}, \mathrm{t}(11 ; 12)(\mathrm{q} 22 ; \mathrm{q} 22)$ described as a TS karyotype. Turner patients usually have normal intelligence; however, moderate to severe levels of mental retardation were found in 5 TS cases, which is considerate a very uncommon feature in this syndrome.

Key words: Mosaicism; Chromosomal abnormality; X-monosomy; Balanced translocation

\section{INTRODUCTION}

Turner syndrome (TS) is one of the most common chromosomal disorders, characterized by the absence or abnormality of one sex chromosome either in all or some cells. This genetic disorder is caused by haploinsufficiency of genes normally expressed in both X chromosomes, which are involved in the physical development and maintenance of ovarian function in patients with female phenotype, affecting approximately 1/2500 live-born girls (Stochholm et al., 2006).

According to cytogenetic reports, chromosome monosomy $(45, \mathrm{X})$ is found in $50-60 \%$ of cases. Other karyotypes with structural changes in the $\mathrm{X}$ chromosome are present in approximately $30 \%$ of cases, including isochromosome of the long arm, deletion of the short arm or ring chromosomes, either in homogeneous karyotypes or in mosaics with a 45,X cell line (Oliveira et al., 2009; Djordjević et al., 2010; Elleuch et al., 2010). Patients with TS may also have a second cell line with a normal or abnormal Y chromosome in 5 to $6 \%$ of cases (Gravholt, 2005). On the other hand, few cases exhibit complex karyotypes, which may include the formation of derivatives of the X chromosome (Binkert et al., 2010; Burégio-Frota et al., 2010).

The clinical profile of TS is evidenced by short stature and gonadal dysgenesis, leading to delayed pubertal development, primary amenorrhea and sterility. Furthermore, a variety of dysmorphic features may be present, such as lymphedema of hands and feet, short and/or webbed neck, cubitus valgus, low posterior hairline, low-set ears, widely spaced nipples, ogival palate, ptosis, epicanthal folds, and hypoplasia of the fourth or fifth metacarpal and metatarsal bones (Sybert and McCauley, 2004; Hjerrild et al., 2008). In addition, this syndrome may involve various malformations, especially in the heart (most commonly coarctation of the aorta) and the kidneys, besides hearing impairment, hypertension, thyroid disease, and obesity (Bondy, 2009; Davenport, 2010).

In view of the importance of establishing genotypic and phenotypic correlations for appropriate management of TS patients, this study reports a detailed cytogenetic and clinical analysis of patients with Turner syndrome to provide new information on the developmental effects of different chromosome constitutions and their role in the expression of TS phenotype. Additionally, this study reports on the rare genetic and phenotypic abnormalities associated with this syndrome.

\section{MATERIAL AND METHODS}

From May 2006 to December 2011, cytogenetic analyses were performed in 65 pa- 
tients with clinical indication of TS, who were seen in the Service of Medical Genetics at the Institute of Integral Medicine Professor Fernandes Figueira and in the Service of Pediatric Endocrinology at Hospital das Clinicas of the Federal University of Pernambuco. The cytogenetic study was based on cell culture from phytohemagglutinin-stimulated peripheral lymphocytes using standard procedures. Detailed clinical data for patients were obtained by either physical examination of review of medical records. Once the syndrome was confirmed, most patients underwent ultrasound and cardiologic evaluation. Statistical analyses were performed by the Fisher test, comparing the patients with $45, \mathrm{X}$ and those with other non-normal karyotypes. $\mathrm{P}<0.05$ was considered statistically significant.

This study was designed according to the guidelines and regulatory norms of Brazil's National Health Council for research involving human subjects and Resolution No. 196 of October 10, 1996. Informed consent was obtained from all patients or their parents. The project was approved by the Ethics Committee (Record: CEP/IMIP No. 802/06).

\section{RESULTS}

The karyotype distribution of 65 TS patients is shown in Table 1. The most common was the monosomic karyotype $(61.5 \%)$. Structural changes in the X chromosome together with mosaicism were observed in $24.5 \%$ and mosaic karyotypes without structural anomalies, which also included the $\mathrm{Y}$ chromosome, were found in $7.5 \%$ of the patients. Isochromosome $\mathrm{Xq}$ was the most frequent structural change observed in $23.1 \%$ in either mosaics (45,X cell line) or in homogeneous karyotypes.

Table 1. Distribution of karyotypes associated with Turner syndrome.

\begin{tabular}{lcc}
\hline Karyotype & No. of patients & Frequency $(\%)$ \\
\hline $45, \mathrm{X}$ & 40 & 61.5 \\
Mosaics without structural changes & 1 & 1.5 \\
45,X/46,XX & 1 & 1.5 \\
45,X/47,XXX & 11 & 16.9 \\
Mosaics with structural changes & 2 & 3.1 \\
46,X,i(Xq)/45,X & 1 & 1.5 \\
46,X,r(X)/45,X & 1 & 1.5 \\
46,X,del(Xp)/45,X & 1 & 1.5 \\
46,X,inv dup $(\mathrm{Xq}) / 45, \mathrm{X}$ & 3 & 4.6 \\
45,X/46,X,+mar & & 6.2 \\
Mosaics with Y chromosome & 4 & 100.0 \\
45,X/46,XY & 65 & \\
Structural change without mosaicism & & \\
46,X,i(Xq) & & \\
Total &
\end{tabular}

The age of TS patients at the moment of diagnosis ranged from newborn to 35 years old, but in most cases TS was diagnosed at the age of puberty or beyond (9-18 years old). In general, TS was confirmed early in patients with X-monosomy, where in almost $40 \%$ of these cases, the karyotype was established before the age of two (Table 2). However, in most patients with mosaicism and/or X structural changes (77.3\%), cytogenetic analyses were not done until the age of puberty. 
Table 2. Frequency distribution of age at the moment of chromosome analysis.

\begin{tabular}{lccc}
\hline Age & $45, \mathrm{X}$ & Other karyotypes & All TS cases \\
\hline $0-2$ years & $39.5 \%$ & - & $25 \%$ \\
$3-8$ years & $2.7 \%$ & $22.7 \%$ & $10 \%$ \\
$9-13$ years & $21.0 \%$ & $18.2 \%$ & $20 \%$ \\
$14-17$ years & $21.0 \%$ & $31.8 \%$ & $25 \%$ \\
$\geq 18$ years & $15.8 \%$ & $27.3 \%$ & $20 \%$ \\
\hline
\end{tabular}

$\mathrm{TS}=$ Turner syndrome

Webbed neck (92.31\%), lymphedema of hands and feet (84.62\%), congenital heart disease $(61.53 \%)$ and nail hypoplasia $(53.85 \%)$ were the main clinical features that led to cytogenetic analyses before the age of two in $45, \mathrm{X}$ patients. Our results demonstrated that at birth these were the predominant phenotypic determinants of this syndrome.

In $89.3 \%$ of all cases, short stature was the most frequent phenotypic characteristic. This growth failure was more frequent among patients with monosomy as compared to those who showed mosaicism (Figure 1), but this difference was not statistically significant ( $\mathrm{P}=$ 0.486). Another important clinical feature was gonadal dysgenesis with delayed pubertal and primary amenorrhea, which was observed in $84.8 \%$ of TS patients at pubertal age. This clinical disorder was observed in all patients with mosaicism in contrast to carriers of X-monosomy (Figure 1), with the difference being statistically significant $(\mathrm{P}<0.001)$.

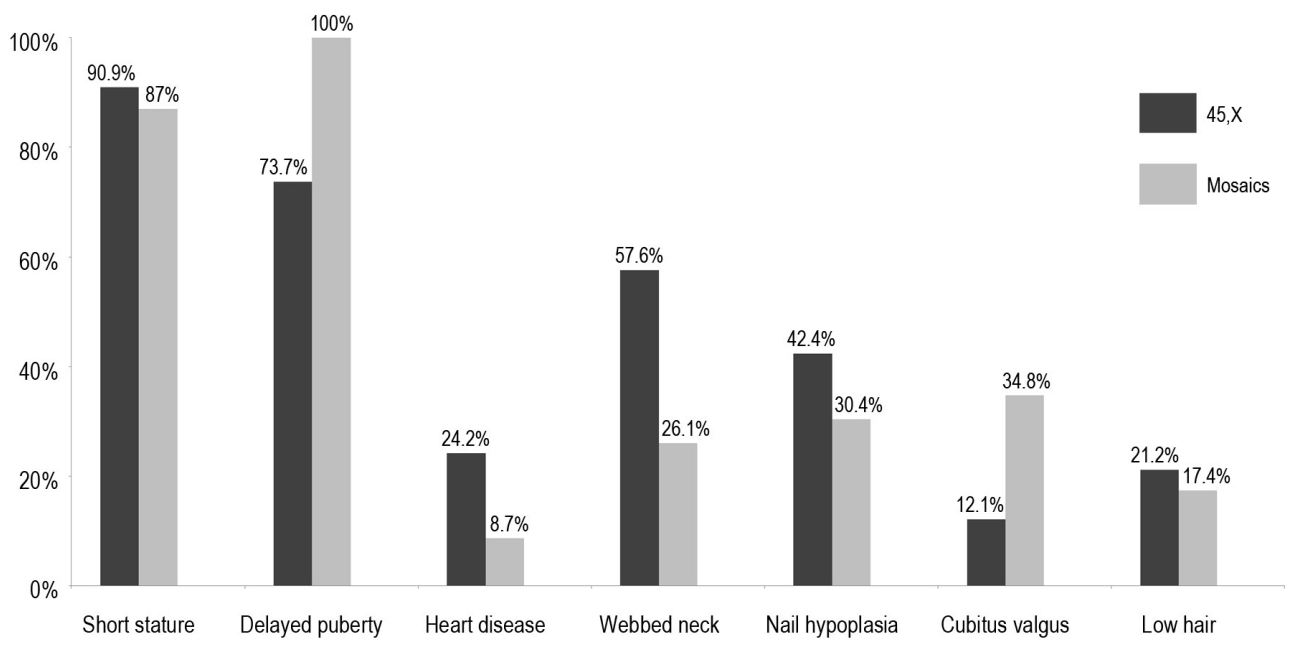

Figure 1. Distribution of the most prevalent clinical features according to karyotype constitution.

Congenital heart disease, another important TS-related clinical factor, was found in $17.9 \%$ of cases, where it was significantly more frequent in monosomic karyotypes (Figure 1) $(\mathrm{P}=0.007)$. Autoimmune diseases such as Hashimoto's thyroiditis $(12.5 \%)$ and renal malformations $(8.93 \%)$ were also observed in the subjects.

Although TS patients may have nonverbal learning disabilities, average intellectual per- 
formance is usually normal. Nevertheless, we found moderate and severe mental retardation in 2 and 3 of 65 TS patients (7.7\%), respectively. The karyotypes associated with this rare stigma included 45,X (three cases), 45,X,t(11;12)(q22;q22) (one case) and 46,X,i(Xq)/45,X (one case).

Several dysmorphic features were observed, such as widely spaced nipples, epicanthal folds, shortening of the metacarpal bones and high arched palate. The most common phenotype of all TS patients was short and webbed neck (44.6\%), hypoplastic nails (37.5\%), low posterior hairline (19.6\%), and cubitus valgus (21.4\%), with the latter being more common in patients with mosaicism (Figure 1). However, only short and webbed neck $(\mathrm{P}<0.001)$ and cubitus valgus $(\mathrm{P}=$ 0.0002 ) showed statistically significant differences between mosaics and 45,X cases.

We also found one TS patient with unusual cytogenetic constitution displaying the following karyotype: $45, \mathrm{X}, \mathrm{t}(11 ; 12)(\mathrm{q} 22 ; \mathrm{q} 22)[20]$. Clinical examination at the age of 33 showed short stature, short and webbed neck, low posterior hairline, primary amenorrhea and mental retardation; she neither knew her age nor recognized colors. Karyotype analysis of the parents was not possible.

\section{DISCUSSION}

Turner syndrome is a chronic disease associated with a wide range of malformations with varying frequencies, which are mainly related to the type of $X$ chromosome rearrangement. Our cytogenetic analyses of 65 TS patients corroborated, in general, previously reported data (Held et al., 1992; Schoemaker et al., 2008; Djordjević et al., 2010; Elleuch et al., 2010). However, our patient sample had only one case $(1.5 \%)$ of mosaicism with a normal cell line $(46, \mathrm{XX})$, which is significantly lower than frequencies described in the literature (8 to $17 \%$ ). Although reports of TS patients with X duplications and balanced translocation are very rare, we found two of these karyotypes displaying these uncommon chromosomal rearrangements.

The case of X-duplication (Table 1) previously reported by our research group (Burégio-Frota et al., 2010) showed classical TS stigmata associated with the karyotype 46,X,inv $\operatorname{dup}(X)($ pter $\rightarrow \mathrm{q} 22:: \mathrm{q} 22 \rightarrow$ pter $) / 45, X$. Partial X-chromosome duplications are relatively infrequent and occur predominantly in men, where they are associated with multiple congenital abnormalities (Cheng et al., 2005). Few cases of dup(Xq) have been described in females, and the abnormal phenotype usually includes short stature, developmental delay, hypogonadism and other dysmorphic anomalies. As a consequence of selection against cells with abnormal $\mathrm{X}$ in carrier females, most $\operatorname{dup}(\mathrm{Xq})$ are inactivated, and females appear phenotypically normal (Armstrong et al., 2003; Stankiewicz et al., 2005). In our dup(Xq) case, we believe that the clinical data observed in this patient were probably due to the 45 ,X cell line.

Balanced translocations are rare chromosome rearrangements and seldom found in TS. To the best of our knowledge, this is the first case of TS describing a balanced translocation involving chromosomes 11 and 12, karyotype 45,X,t(11;12)(q22;q22). To date, only seven cases of balanced translocations in $45, \mathrm{X}$ cell line have been reported. Using high resolution banding, Ozkul et al. (2002) found a TS infant with the karyotype 45X,t(1;2)(q41;p16), and one case of TS with familial balanced translocation $\mathrm{t}(1 ; 2)(\mathrm{q} 32 ; \mathrm{q} 21)$ mat was described by Kondo et al. (1979). Four other studies reported an association of X-monosomy with balanced Robertsonian translocation t(13;14) (Laszlo et al., 1984; Salamanca et al., 1985; Krajinovic et al., 1994; Silva et al., 2006). Recently, Djordjević et al. (2010) showed a case of 45,X,t(1;9) (cen;cen) in combination with a $\mathrm{r}(\mathrm{X})$ mosaic karyotype. 
Usually, balanced chromosomal translocations do not exhibit any phenotypic abnormalities. However, their carriers may have increased reproductive risk, with spontaneous abortions. In our case, the patient had a typical 45, X lineage TS phenotype. Since the X-monosomy is related to normal intelligence, we suggest that the $\mathrm{t}(11 ; 12)$ could be responsible for the mental disability in this patient. Mutations in several genes have been associated with mental retardation (Kalscheuer et al., 2009; Vandeweyer and Kooy, 2009), but in our case it may have been the loss of genetic information by the translocation process that may have caused mental disability.

Short stature is considered the most common feature, which affects over $90 \%$ of recognized patients (Bondy, 2009; Oliveira et al., 2009; Davenport, 2010). This growth failure was indeed the most consistent phenotypic characteristic in our study, regardless of their karyotype. In two patients, only this phenotype led us to test for TS, pointing to the importance of correlating age with anomalous height and confirming TS in girls with growth failure. Short stature and other skeletal abnormalities seen in TS occur due to haploinsufficiency of the SHOX gene, which is located at Xp22 and Yp11.3, in the pseudoautosomal region of the sex chromosomes (Ogata et al., 2002).

Gonadal dysgenesis was the second most important TS stigma found in this study. This occurs in most TS individuals and is mainly caused by the haploinsufficiency of genes located on the long arm of the X chromosome, Xq26 (POF1) and Xq13-21 (POF2), which are involved in the maintenance of the ovaries. In contrast, a deletion of the distal short arm is usually compatible with normal ovarian function (Davison et al., 2000; Pienkowski et al., 2008). Even though most genes of ovarian function remain active in the $\mathrm{i}(\mathrm{Xq})$, all patients with this chromosome rearrangement exhibited gonadal disorders, which might have been attributed to hidden or gonad-confined mosaicism.

Congenital cardiovascular defects are the most life-threatening medical problem faced by TS patients and are found in 25 to $50 \%$ of them (Morgan, 2007; Bondy, 2009). Adults with TS have a 4- to 5-fold increased rate of premature mortality, which is attributed mainly to complications of congenital heart disease (Stochholm et al., 2006; Schoemaker et al., 2008). There was a significantly higher incidence of congenital heart disease in monosomic karyotypes $(24.2 \%)$ compared with mosaics $(8.7 \%)$, showing the association of the more severe phenotype with a 45,X cell line. In contrast, Tan and Yeo (2009) examined the frequency of congenital cardiac defects in TS patients from Singapore and found no statistical difference between monosomic and different structural mosaics.

Turner patients usually have normal intelligence, but may have difficulty with nonverbal, social, and psychomotor skills (Morgan, 2007). However, in few cases there may be mental retardation with severe congenital malformations associated with tiny ring $\mathrm{X}$ chromosome. This unusual clinical presentation is related to the deficiency in inactivating this tiny $r(X)$ due to the absence of the X-inactivation center, causing the disomy of several genes, which alters the dosage compensation mechanism. The preferably inactivated $r(X)$ is therefore associated with normal intelligence (El Abd et al., 1999; Suzigan et al., 2005). Thus, the mental retardation observed in 5 TS cases in our study was a very uncommon feature, since their karyotype did not show the tiny $\mathrm{r}(\mathrm{X})$. Mental retardation could be related to this additional rearrangement only in one of the 5 patients who had an additional chromosomal change t(11q;12q). The other 4 cases remain unexplained.

The genetic and phenotypic correlation of dysmorphic features, autoimmune diseases and renal malformations proved to be inconsistent, since most of these clinical data did not 
show statistical differences between monosomic and mosaic TS patients. The TS phenotype is attributed to haploinsufficiency of genes that are normally expressed in both the active and inactive X-chromosomes. However, some reports indicate that other factors, not yet fully elucidated, may influence phenotypic expression, including hidden mosaicism, genomic imprinting or anomalous $\mathrm{X}$ inactivation, leading to difficulties in diagnosis and genetic counseling (Araújo and Ramos, 2008; Oliveira et al., 2009).

In conclusion, the patients with 45 , X karyotype exhibited a tendency to have more severe phenotypes than those with mosaicism. Thus, our study confirms the association of higher morbidity with X-monosomy, showing that this karyotype plays an important role in the prognosis of Turner syndrome. Additionally, the presence of mental retardation in five of our patients associated with classical TS phenotype indicates that this mental disability could be an additional rare feature associated with TS and should be considered more carefully by physicians.

\section{ACKNOWLEDGMENTS}

Research supported by Fundação de Amparo à Ciência e Tecnologia do Estado de Pernambuco (FACEPE - APQ \#0335-2.02/06). The authors thank the patients, parents and clinicians for the data.

\section{REFERENCES}

Araújo A and Ramos ES (2008). Cryptic mosaicism involving a second chromosome X in patients with Turner syndrome. Braz. J. Med. Biol. Res. 41: 368-372.

Armstrong L, McGowan-Jordan J, Brierley K and Allanson JE (2003). De novo dup(X)(q22.3q26) in a girl with evidence that functional disomy of $\mathrm{X}$ material is the cause of her abnormal phenotype. Am. J. Med. Genet. A 116A: 71-76.

Binkert F, Spreiz A, Höckner M, Miny P, et al. (2010). Parental origin and mechanism of formation of a 46,X,der(X)

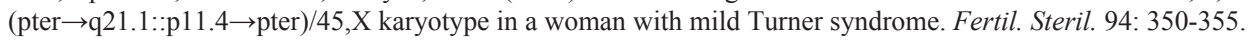

Bondy CA (2009). Turner syndrome 2008. Horm. Res. 71 (Suppl 1): 52-56.

Burégio-Frota P, Valenca L, Leal GF, Duarte AR, et al. (2010). Identification of a de novo inv dup $(X)(p t e r \rightarrow q 22)$ by multicolor banding in a girl with Turner syndrome. Genet. Mol. Res. 9: 780-784.

Cheng SF, Rauen KA, Pinkel D, Albertson DG, et al. (2005). Xq chromosome duplication in males: clinical, cytogenetic and array CGH characterization of a new case and review. Am. J. Med. Genet. A 135: 308-313.

Davenport ML (2010). Approach to the patient with Turner syndrome. J. Clin. Endocrinol. Metab. 95: 1487-1495.

Davison RM, Fox M and Conway GS (2000). Mapping of the POF1 locus and identification of putative genes for premature ovarian failure. Mol. Hum. Reprod. 6: 314-318.

Djordjević VA, Jovanović JV, Pavković-Lučić SB, Drakulić DD, et al. (2010). Cytogenetic findings in Serbian patients with Turner's syndrome stigmata. Genet. Mol. Res. 9: 2213-2221.

El Abd S, Patton MA, Turk J, Hoey H, et al. (1999). Social, communicational, and behavioral deficits associated with ring $\mathrm{X}$ turner syndrome. Am. J. Med. Genet. 88: 510-516.

Elleuch M, Mnif FM, Kammoun M, Charfi N, et al. (2010). Descriptive analyses of Turner syndrome: 49 cases in Tunisia. Ann. Endocrinol. 71: 111-116.

Gravholt CH (2005). Clinical practice in Turner syndrome. Nat. Clin. Pract. Endocrinol. Metab. 1: 41-52.

Held KR, Kerber S, Kaminsky E, Singh S, et al. (1992). Mosaicism in 45,X Turner syndrome: does survival in early pregnancy depend on the presence of two sex chromosomes? Hum. Genet. 88: 288-294.

Hjerrild BE, Mortensen KH and Gravholt CH (2008). Turner syndrome and clinical treatment. Br. Med. Bull. 86: 77-93.

Kalscheuer VM, Musante L, Fang C, Hoffmann K, et al. (2009). A balanced chromosomal translocation disrupting ARHGEF9 is associated with epilepsy, anxiety, aggression, and mental retardation. Hum. Mutat. 30: 61-68.

Kondo I, Hamaguchi H, Matsuura A, Nakajima H, et al. (1979). A case of Turner's syndrome with familial balanced translocation $\mathrm{t}(1 ; 2)(\mathrm{q} 32 ; \mathrm{q} 21)$ mat. J. Med. Genet. 16: 321-323.

Krajinovic M, Ivanovic K, Mestroni L, Diklic V, et al. (1994). Parental origin of the X chromosome in a patient with a Robertsonian translocation and Turner's syndrome. J. Med. Genet. 31: 255-256. 
Laszlo J, Bosze P, Gaal M and Toth A (1984). A case of 44,X streak gonad syndrome combined with familial balanced 13/14 translocation. Acta Med. Hung. 41: 223-227.

Morgan T (2007). Turner syndrome: diagnosis and management. Am. Fam. Physician 76: 405-410.

Ogata T, Muroya K, Sasaki G, Nishimura G, et al. (2002). SHOX nullizygosity and haploinsufficiency in a Japanese family: implication for the development of Turner skeletal features. J. Clin. Endocrinol. Metab. 87: 1390-1394.

Oliveira RM, Verreschi IT, Lipay MV, Eca LP, et al. (2009). Y chromosome in Turner syndrome: review of the literature. Sao Paulo Med. J. 127: 373-378.

Ozkul Y, Atabek ME, Dundar M, Kurtoglu S, et al. (2002). A Turner patient with a 45,X,t(1;2) (q41;p11.2) karyotype. Ann. Genet. 45: 181-183.

Pienkowski C, Menendez M and Cartault A (2008). Syndrome de Turner et procréation. Gynecol. Obstet. Fertil. 36: 1030-1034.

Salamanca F, Buentello L, Sanchez J and Armendares S (1985). A patient with 44 chromosomes. Ann. Genet. 28: 130-132.

Schoemaker MJ, Swerdlow AJ, Higgins CD, Wright AF, et al. (2008). Mortality in women with turner syndrome in Great Britain: a national cohort study. J. Clin. Endocrinol. Metab. 93: 4735-4742.

Silva AL, Lima RLLF, Ribeiro LA and Moretti-Ferreira D (2006). X monosomy and balanced Robertsonian translocation in a girl with Turner Syndrome. Genet. Mol. Biol. 29: 47-48.

Stankiewicz P, Thiele H, Schlicker M, Cseke-Friedrich A, et al. (2005). Duplication of Xq26.2-q27.1, including SOX3, in a mother and daughter with short stature and dyslalia. Am. J. Med. Genet. A 138: 11-17.

Stochholm K, Juul S, Juel K, Naeraa RW, et al. (2006). Prevalence, incidence, diagnostic delay, and mortality in Turner syndrome. J. Clin. Endocrinol. Metab. 91: 3897-3902.

Suzigan LZC, Silva RBP and Guerra AT (2005). Aspectos psicossociais da síndrome de Turner. Arq. Brás. Endocrinol. Metab. 49: 157-164.

Sybert VP and McCauley E (2004). Turner's syndrome. N. Engl. J. Med. 351: 1227-1238.

Tan KB and Yeo GS (2009). Pattern of Turner syndrome in Singapore (1999-2004). Singapore Med. J. 50: 587-590.

Vandeweyer G and Kooy RF (2009). Balanced translocations in mental retardation. Hum. Genet. 126: 133-147. 